ELUA

ISSN 2171-6692

Núm. 35, 2021, págs. 349-354

https://doi.org/10.14198/ELUA2021.35.20

\title{
ATTARDO, SALVATORE (2020). THE LINGUISTICS OF HUMOR: AN INTRODUCTION, OXFORD: OXFORD UNIVERSITY PRESS. ISBN: 9780198791287. 496 PÁGINAS.
}

\author{
Alicia Silvestre Miralles \\ Universidad de Zaragoza, España \\ aliciasi@unizar.es \\ https://orcid.org/0000-0002-2923-9424
}

Si hay algo que caracteriza al género humano además del lenguaje, es la poesía, la religión y el humor. Es en esos ámbitos donde hace gala de su excepcionalidad y creatividad, y es justo en esos dominios donde la ciencia lingüística trastabilla cuando pretende sistematizar, hallar reglas o explicar sus fenómenos.

Ya desde el título, el autor hace gala de humildad al presentar esta obra como una mera introducción. Así sucede cuando uno investiga sobre un tema toda una vida: ve la punta del iceberg y se da cuenta de que queda mucho por pergeñar. Su trabajo de 1994, Linguistic theories of humor, en Mouton de Gruyter, marcó un hito bibliográfico por su visión panorámica y de largo alcance acerca de la investigación en humor, de manera global e histórica. Ninguna obra hasta entonces había osado emprender tal tarea. Ha esperado 26 años para renovar contenidos y presentarnos este volumen de más de 400 páginas, maduro, exhaustivo (en la medida en que un asunto en abierto puede serlo), y definitivamente actualizado. Enhebrando disciplinas aparentemente dispares, asedia el tema desde diversas perspectivas, no perdiendo el foco, y demostrando la futilidad de un enfoque monocular ante un asunto tan dispar. Lo más cerca que podremos estar de la verdad acerca del humor, se consigue precisamente con un enfoque multidisciplinar, con metodologías variadas que pongan a prueba teorías y que no se conformen con una descripción trivial o parcial. Ahí radica una de sus genialidades: "What defines interdisciplinarity is that both the questions and the methodologies come from a variety of disciplines" (p. 21).

Salvatore Attardo no ha sido solo un aguerrido pionero, sino que ha mantenido durante décadas su pasión investigadora, sin amilanarse ante lo vasto e interdisciplinar de la cuestión del humor y el lenguaje. Hoy por hoy, no es posible hablar de ello sin referirle. Se ha ganado un respetable lugar dentro de unos estudios que él mismo ha contribuido a consolidar como área de conocimiento independiente con sus numerosos trabajos. A justificarlo como ciencia acude el capítulo 1.2., en el que documenta las obras que desde la Antigüedad acometieron

Para citar esta reseña: Silvestre Miralles, Alicia (2021). Salvatore Attardo. The Linguistics of Humor: an Introduction, Oxford: Oxford University Press. ELUA, 35: 349-354. https://doi.org/10.14198/ ELUA2021.35.20

(C) 2021 Alicia Silvestre Miralles 
el humor como teoría, categoría o género. Las primeras obras con mirada científica datan de mediados de los setenta. A ello confluyen los congresos específicos, las asociaciones (ISHS, WHIM), las revistas especializadas (Humor, 1988), los manuales u obras de referencia (Encyclopedia of Humor Studies de 2015 y Handbook of Language and Humor de 2017) y, en fin, la aparición de asignaturas en la universidad.

Sus numerosas publicaciones, individuales y conjuntas, demuestran su saber hacer académico y su capacidad para relacionar, sin excluir, tópicos que, en principio, pudieran parecer opuestos. Hacer ciencia, creemos, tiene más que ver con esto que con taxonomías restrictivas, y más si cabe en un fin como el humor. Nos encontramos, por tanto, ante una obra de madurez precedida de acendrada investigación sobre la lingüística del humor.

Si el tema del libro no fuera por sí mismo ameno, el estilo suma: una prosa ligera y especiada, un lenguaje accesible, divulgativo, que no teme hacer uso del humor en su discurso, sin sobrecarga. Con ello no menoscaba la pulcritud científica del discurso académico ni su necesaria reflexión y profundidad: antes bien, rompe, elegantemente, sus rigideces y frialdades. Semántica y conceptualmente, concisión y relevancia guían el discurso: nada de pompa o artefacto. Lo simple y directo, es preferido: "We will shelve the unnecessarily complex apparatus" (p. 7). Es por este motivo, entre otros, por lo que emplea el humor como término "paraguas" ("umbrella term"), pues argumenta que "there is no reason to coin a new term if there is a perfect good one already" (p. 8).

Una exacerbada visión de conjunto permite exponer las dicotomías intrínsecas de esta área de conocimiento: "The naturally occurring data linguists mock the first linguist as "armchair" linguists and decry the "artificial nature of the data [...] the armchair linguists mock the inherent limitations of finite corpora and restricted samples" (p. 24).

El índice de contenidos anuncia, con la aparición de términos generativos (competencia, actuación) que en sus Preliminares metodológicos va a utilizar dicho marco, en consonancia con sus trabajos de las últimas décadas. Vale la pena realzar la distinción terminológica del capítulo dos, a la hora de aportar rasgos discriminativos entre los diversos géneros y subgéneros del humor y que para un lego en la materia son sinónimos: broma, chiste, humor, sarcasmo, ironía, etc. Resultan apasionantes algunas extensiones hacia otras disciplinas como la neurolingüística, las teorías evolucionistas, las antiesencialistas, además de la base psicológica, sin soslayar la semiótica y la pragmática del humor.

Cada capítulo va acompañado de lecturas para profundizar y conclusiones. Se compone de cuatro grandes bloques temáticos (Humor studies, Humor competence, Humor performance, Applications), que van precedidos de sus correspondientes introducciones. El libro posee una inclinación claramente pedagógica, como indica el autor en el prefacio. En total son dieciséis capítulos (más las conclusiones), donde se extiende sobre la teoría general del humor verbal (TGHV) establecida por Attardo y Raskin en 1991 y posteriormente revisada por Ruiz Gurillo en 2012. La sabia apertura en cada capítulo se completa paralelamente con recientes hallazgos y novedades en investigación.

En su panorámica sobre los estudios del humor (1.2), se retrotrae a los egipcios y sumerios. Destaca algunas figuras en la Edad Media y en el Renacimiento italiano. Hemos echado en falta la mención de la picaresca española. Nuestro folclórico Lazarillo y el eros ludens de la Celestina trotaconventos no desmerecen a lo escrito por Rabelais en Francia, Erasmus en Alemania o Shakespeare en Inglaterra (p. 19). Cita después a Descartes, Hobbes, y a pilares como Freud, Pirandello y Bergson. 
El segundo capítulo se adentra en las manifestaciones que permiten reconocer e identificar el humor, y nos deleita con subcapítulos sobre la sonrisa (smile) y la risa (laughter). El término que elige es la alegría (mirth) y pasa a diferenciar entre la risa alegre y la no alegre (mirthful vs. non-mirthful laughter) (p. 42), recordando que "laughter largely exceeds humor" (p. 43) y desaconsejando, metodológicamente, que consideremos como algo humorístico por el mero hecho de que a alguien le cause risa (p. 46). De hecho, hay dos tipos de respuestas: afectiva o cognitiva. Estas respuestas hallan su correspondencia en la prueba neurológica que distingue entre reconocimiento y apreciación (p. 47). Resume que para que un texto humorístico sea considerado tal, la incongruencia ha de respetar algunos factores: no ser amenazadora, no ser demasiado simple ni demasiado compleja, basarse en conocimiento disponible o guiones/marcos, ser sorprendente o inesperada, ocurrir en un modo distendido (playful) y ser repentina (p. 50). A continuación pasa a detenerse en cada una de estas frases y profundiza en el humor intencional, la triangulación, el humor fallido (failed humor). En todo momento mantiene la atención terminológica y metodológica con reflexiones ponderadas para justificar su discurso y apuntalar la teoría.

El tercer capítulo nos adentra en las teorías del humor y sus niveles. Parte de una especie de declaración de principios y se reconoce a favor de las teorías de corte reduccionista o esencialista, que para él consisten en la búsqueda de los rasgos necesarios y suficientes que causan un fenómeno (p. 58). Considera dos polos dentro de un espectro: de un lado el nivel neurológico, que se caracteriza por un mayor determinismo y, por otro lado, las teorías macrosociológicas en el extremo contrario. Luego aborda las que considera ser las tres teorías del humor más relevantes: las de la incongruencia (incongruity), las de la hostilidad o agresividad (hostility) y las de la liberación o catarsis (release). En estas últimas cita a Grice y su Principio de Cooperación. En las segundas cita a Freud (1905) y el humor inocente/blanco, (innocent or non-tendentious humor) (p. 65). Acaba el subcapítulo sobre el humor agresivo matizando que solo una parte del humor es de este tipo. Aporta datos actuales y teorías punta, innovadoras (cutting edge), como las que encontramos en los párrafos dedicados a la neurolingüística del humor (p. 68). Tras presentar, describir brevemente y evaluar cada una de las corrientes, incluye un apartado conclusivo que titula "Complementariedad de las teorías del humor" (p. 71) y que en cierto modo anticipa sus conclusiones, en dirección a una Über-Theorie.

Algunos axiomas base jalonan la reflexión: uno de ellos es que el humor sucede dentro de un sistema semiótico-referencial (p. 74). Otras, que el significado es un asunto semántico y no lingüístico (p. 81), pues excede al lenguaje y que el humor tiene naturaleza comunicativa (p. 95).

El cuarto capítulo entra de lleno en la "Incongruencia y resolución", resaltando que la propia definición de la incongruencia presupone unas expectativas. Diferencia entre las teorías del humor propiamente dicho y las teorías de la incongruencia. Posteriormente se introduce en el tema de la resolución, y va citando su historia (Freud, Aubouin, Ziv, Forabosco, Oring) y concluye con su GTVH (Attardo \& Raskin, 1991). Otra nueva puntualización terminológica: define los límites entre las bromas/chistes y las adivinanzas/enigmas (jokes and riddles). Solo en las segundas la incongruencia se ve resuelta plenamente. No olvida el modelo de isotopía y disfunción (Greimas, 1966) de donde toma prestados los términos de "conector" y "disyuntor" (connector, disjunctor). Sirve como antecedente para explicar el surgimiento de los marcos y redes semánticas (scripts/frames), así como los "schemata". 
El capítulo quinto, sobre la semiótica del humor, proporciona una definición perlocutiva del mismo, esto es, enfatiza las intenciones del hablante y del oyente. Destaca la desfuncionalización (defunctionalization) del signo, en que se nos remite a Jakobson $(1960,1987)$. Explica la diferencia entre semántica y semiótica del humor y alude al humor musical.

Comienza con el capítulo seis la segunda parte, referida a la competencia humorística (competence). En ella desarrolla la teoría del guión semántico que es un antecedente de la teoría general del humor verbal y que parte de la teoría de Raskin de 1985. Tras las necesarias acotaciones terminológicas entre guión y marco (script/frame) y referencia a Fillmore (1985), nos introduce a la noción de guión y a la organización del conocimiento como red semántica a partir de Peirce y Eco. Desmenuza luego la definición en sus términos: nodo, conexión, red semántica, nodos relacionados, cluster organizado. Hay espacio para la sorpresa: la naturaleza fractal de los guiones, en cuanto a su recursividad como estructuras incrustadas. Vuelve a mencionar la disonancia cognitiva, con la cual los seres humanos suelen reaccionar cuando se enfrentan a información de tipo conflictivo para intentar resolverlo, bien compartimentando la información o bien eliminando parte de ella. Para entender el alcance de la activación implícita recurre a los conceptos pragmáticos de inferencia, presuposición e implicatura. Los guiones, explica, pueden ser activados léxicamente, mediante una extensión de la activación, o bien inferencialmente. En resumen, la teoría del humor basada en el guión semántico se apoya en dos premisas fundamentales que son, por un lado, que el texto es compatible en todo o en parte con dos guiones diferentes y, en segundo lugar, que los dos guiones con los cuales el texto es compatible son opuestos o bien se solapan en todo o en parte. Es entonces cuando analiza los conceptos de oposición y de solapamiento.

A continuación, ofrece un análisis de algunos asuntos metodológicos que han sido criticados o superados en la teoría del humor del guion semántico. Nos presenta la hipótesis de que el humor es un modo de comunicación non bona fide. Cierra el capítulo seis con una alusión a la semántica ontológica de la teoría del humor y su aplicación al humor computacional.

La mayoría de las explicaciones vienen acompañadas de exhaustivos análisis de bromas y chistes a la luz de las teorías propuestas y no resulta poco común que la misma broma aparezca en varios capítulos vista desde diferentes perspectivas, lo que ayuda a comprender la complejidad y profundidad de los diferentes enfoques y del hecho humorístico como tal.

Por fin, el capítulo séptimo se extiende sobre su Teoría General del Humor Verbal, ya apuntada en su obra de 1994 y completada en posteriores publicaciones, pero que en este volumen encuentra una actualización, mejora y ejemplificación más amplia. Reconoce que la idea surge a partir de la teoría del humor de Raskin, la cual no diferenciaba entre humor verbal y referencial, por lo que no era posible generalizar dicha teoría. Los recursos de conocimiento vienen identificados y son seis: la oposición de guiones, el mecanismo lógico, la situación, el objetivo, la estrategia narrativa y el lenguaje.

Con la misma coherencia que ha seguido anteriormente, define y trata en subcapítulos específicos cada uno de estos conceptos desglosando la idea inicial. Destaca el hecho de que explica algunas posibles ampliaciones de la teoría, sobre todo en hipótesis que se refieren a los correlatos neurológicos, la aplicación de dicha teoría a textos más largos y algunas notas metodológicas sobre la elección de elementos para investigación, entre otros.

En el capítulo octavo comienza su exposición sobre la pragmática del humor. Se apoya en tres supuestos: el primero es que todas las diferencias de significado pueden ser utilizadas para la creación de humor; el segundo, que todo tipo de humor está basado semánticamente 
y el tercero, que el humor puede producirse a partir de la sola violación de las reglas pragmáticas (p. 157). Tras una introducción a los principios pragmáticos, los actos de habla, las implicaturas y lo implícito, se adentra en la naturaleza de la violación del principio de cooperación de Grice, concluyendo que el humor es, en esencia, no cooperativo (non bona fide), característica que comparte, por ejemplo, con la ficción. El Principio de Interrupción Mínima (Least Disruption Principle) (p. 166) propuesto por Attardo (1999) y Eisterhold et al. (2006) se sostiene en una supermáxima: "minimice su violación del Principio de Cooperación". Dedica varias páginas al trato de la ironía. Luego declara que todo humor es intencional y alude al principio de Caridad (Jackman, 2003) (p. 172).

El capítulo noveno, dedicado al humor verbal, comienza aclarando que este no equivale a humor verbalizado, término este último que se emplea sobre todo para diferenciarlo del humor visual o del humor multimodal. La gran diferencia radica en que el humor verbal está centrado en el significante, o, dicho de otra manera, en el soporte fonémico del lenguaje, por lo que se opone al humor referencial (que no requiere ninguna atención especial hacia la forma lingüística). Muchos lingüistas acudirán a este capítulo para buscar la definición de "pun" y su clasificación. A continuación, lista varias maneras en que, en los textos, pueden coaparecer dos significados: mediante la ambigüedad (léxica, sintáctica, referencial, pragmática, entre otras), mediante el posicionamiento sintagmático, mediante la paronimia y la distancia fonética o mediante conectores y disyuntores. Por último, incluye algunas nociones sobre la interpretación, el cratilismo y el abordaje psicolingüístico de los "puns".

El capítulo décimo da inicio a la tercera parte, que se centra en la actuación del humor (humor performance). Proyecta un poco de historia de los autores: Carrell, Rutter, Norrick y por fin la GTHV, además de algunas aproximaciones sociolingüísticas, como el modelo de Hymes-Gumperz.

Los capítulos décimo y undécimo discurren sobre el análisis conversacional y el humor en discurso. Son, como reconoce, las áreas más fértiles en cuanto a investigación en lingüística del humor, y la segunda en el tema del humor, a continuación de la psicología. Estos estudios están orientándose paulatinamente hacia el trabajo con corpus.

El capítulo decimotercero trata de la sociolingüística del humor. Como premisa fundamental, está la universalidad del humor. Menciona las teorías variacionistas: género, clase social, edad, dialectos. En resumen, el humor es un constructo social.

Da inicio después la cuarta y última parte de la obra, que versa sobre las aplicaciones de la teoría. El capítulo decimocuarto trata del humor en la literatura.

El capítulo decimoquinto, dedicado al humor y la traducción, no pasa por alto las premisas de fidelidad, traducción literal versus funcional, las escalas de prioridad, los tipos de solución, las técnicas de traducción, la teoría del Skopos, la traducción audiovisual, entre otros tópicos.

El capítulo decimosexto, que cierra el libro, se titula "Humor en el aula" (Humor in the classroom) y tiene un enfoque aplicado eminentemente práctico: es bien sabido hoy en día que las emociones juegan un papel crucial para la memorización y la atención. Sin esperar milagros, admite que el empleo del humor en el aula puede mejorar la actitud del estudiante y su percepción de la experiencia de aprendizaje. "If teachers want to be funny to their students, they will need to work at knowing why, at what, when, and where their students laugh" (p. 380).

Tras el glosario, una abundante y rica bibliografía de casi ochocientas referencias nos deja ante la evidencia de que apenas tres trabajos en español estén en ella, y tampoco consuela la docena de trabajos publicados por autores españoles en inglés y que allí se listan. 
En España contamos con algunos trabajos centrados en la literatura, como el de Introducción a "La risa en la literatura española" (Antología de textos), de Antonio José López Cruces, de 1993, y más recientemente con el grupo de investigación GRIALE de la Universidad de Alicante y los trabajos de sus miembros. Es, por tanto, un campo en plena expansión, con numerosas áreas de interés en abierto y cuyo estudio podrá dilucidar la naturaleza del lenguaje allí donde menos se somete a órdenes binarias: en el humor que, como alarde creativo, resulta plenamente humano.

\section{REFERENCIAS}

Attardo, S. (2020). The Linguistics of Humor: an Introduction, Oxford: Oxford University Press.

López Cruces, J. A. (1993). "La risa en la literatura española". Alicante: Aguaclara. Introducción disponible en: https://www.biblioteca.org.ar/libros/154936.pdf. 